\title{
Tindakan Bullying dalam Komunikasi Antarpribadi Semasa SMA dan Dampaknya pada Nilai Public Speaking dan IPK
}

\author{
Jesica Sharon Agatha, Roswita Oktavianti \\ jesicasharon29@gmail.com,roswitao@fikom.untar.ac.id \\ Fakultas Ilmu Komunikasi Universitas Tarumanagara
}

\begin{abstract}
The act of bullying is one of the dark sides of interpersonal communication. The act of bullying is experienced by many teenagers when hanging out with friends or in life in the family. A person's academic ability in high school tends to be influenced by the conditions of the surrounding environment. As for those who want to be involved in the world of modern communication, the ability of public speaking is an important part of it. This study wants to find out how much frequency the types of bullying experienced by students during high school (SMA), and how these types of bullying have an impact on academic ability and public speaking. The research method used is mixed (Mix Method) to find out how much frequency the type of bullying is towards the victim, and how the type of bullying has an impact on the academic ability and public speaking of the victim. In this study, the respondents selected by the researchers had certain criteria, one of which was the secondsemester students of the Faculty of Communication Sciences at Tarumanagara University. Therefore, the measurement of the respondent's academic ability uses a GPA. Based on the results of the study indicate that the act of bullying has a different impact on the victims. Not a few who experienced a decrease in academic ability and public speaking. The highest frequency of bullying is verbal bullying in the form of physical insults.
\end{abstract}

Keywords: actions of bullying, public speaking, gpa, interpersonal communication.

\begin{abstract}
Abstrak
Tindakan bullying merupakan salah satu sisi gelap dalam komunikasi antarpribadi. Tindakan bullying banyak dialami para remaja ketika bergaul dengan teman-teman atau dalam kehidupan di keluarga. Kemampuan akademis seseorang pada masa SMA cenderung dipengaruhi oleh kondisi lingkungan sekitar. Hal ini menjadi persoalan ketika bullying yang dialami pada saat SMA membawa dampak bagi kemampuan siswa terutama ketika memasuki jenjang perguruan tinggi. Mahasiswa dituntut memiliki kemampuan public speaking selama perkuliahan. Penilaian juga beralih menjadi sistem Indeks Prestasi Kumulatif. Penelitian ini ingin mengetahui seberapa besar frekuensi jenis bullying yang dialami mahasiswa semasa Sekolah Menengah Atas (SMA), dan bagaimana jenis bullying tersebut berdampak pada nilai public speaking dan IPK. Metode penelitian yang digunakan adalah metode campuran. Metode kuantitatif digunakan untuk mengetahui seberapa besar frekuensi jenis bullying pada siswa semasa SMA. Sementara metode kualitatif digunakan untuk menjawab bagaimana jenis bullying tersebut berdampak pada kemampuan public speaking dan nilai IPK mahasiswa. Responden yang dipilih adalah mahasiswa Fakultas Ilmu Komunikasi Universitas Tarumanagara semester dua. Hasil penelitian menunjukkan bahwa tindakan bullying memiliki dampak yang berbeda-beda bagi korbannya. Tidak sedikit yang mengalami penurunan dalam nilai public speaking dan IPK. Frekuensi tindakan bullying dialami mahasiswa semasa SMA adalah bullying verbal berupa hinaan fisik.
\end{abstract}

Kata Kunci: tindakan bullying, public speaking, IPK, komunikasi antarpribadi. 


\section{Pendahuluan}

Manusia sebagai makhluk sosial tidak dapat menjalani kehidupannya secara normal tanpa adanya kehadiran manusia lain yang berinteraksi dengannya (Soekanto, 2010). Hubungan manusia dengan sesamanya menghasilkan kegiatan interaksi sosial. Interaksi sosial merupakan hubungan timbal balik antara individu dengan individu, individu dengan kelompok, dan kelompok dengan kelompok (dalam Muslim, 2013).

Menurut Kathleen S. Verderber dkk. (2007), komunikasi antar pribadi adalah proses yang mana seseorang menciptakan dan mengatur hubungan mereka, melakukan tanggung jawab melalui proses timbal balik dalam menghasilkan makna pesan. Selanjutnya secara mendalam dijelaskan seperti berikut: pertama, komunikasi antar pribadi sebagai suatu bentuk proses. Proses sendiri merupakan bentuk rangkaian tersusun dari sebuah perilaku yang memiliki tujuan yang terus menerus secara berulang. Kedua, komunikasi antar pribadi tergantung kepada makna yang dihasilkan oleh pihak yang bersangkutan. Ketiga, dengan komunikasi kita dapat menciptakan dan mengelola hubungan (dalam Budyatna dan Ganiem, 2011:14).

Dalam hubungan antarpribadi tidak menutup kemungkinan adanya sisi gelap ataupun hambatan persepsi. Beberapa hambatan tersebut diantaranya adalah bias, salah seleksi, tergesa-gesa memutuskan sesuatu atau "rush", emosi, fokus pada halhal negatif, dan lain sebagainya. Rush diartikan sebagai bertindak, bergerak maju, terburu nafsu, atau melakukan kekerasan, atau berlari ke depan untuk menyerang atau menghadapi serangan. Sikap "rush" ini merupakan tindakan yang membuat pelakunya tidak dapat memikirkan sisi positif dan negatif dari apa yang dia lakukan (Liliweri, 2015:238). Tindakan semacam ini yang menyebabkan timbulnya kasus bullying, karena sikap tergesa-gesa yang sebagian besar berdampak merugikan orang lain.

Bullying atau yang diartikan sebagai suatu tindakan perundungan merupakan suatu pola yang terbentuk dikenal sebagai pelecehan. Menurut Crossman, perundungan biasanya mencakup pesan-pesan verbal maupun non-verbal yang negatif, dimana tidak semua orang dapat menerima pesan tersebut dengan respon yang baik. Bentuk intimidasi ini dilakukan berulang kali dengan menyampaikan pesan-pesan negatif atau memberikan ancaman kepada seseorang.

Salah satu dampak negatif dari tindakan perundungan ini adalah menurunnya kepercayaan diri korban, sehingga tidak memiliki keberanian berbicara di depan umum (public speaking). Menurut Bahar, public speaking bukan hanya sekedar kemampuan berbicara di depan audiens yang banyak, akan tetapi bagaimana dapat berbicara dengan cara yang menarik, informatif, dapat mempengaruhi pendengarnya, dan menghibur (dalam Oktavianti, 2019). Selain itu secara lebih mengerucut dampaknya berpengaruh dalam kemampuan seseorang berbicara di depan umum (public speaking). Akibat dari perilaku perundungan yang dilakukan kepada seseorang dapat menurunkan kepercayaan dirinya. Hal ini yang menjadi salah satu penyebab seseorang tidak dapat melakukan public speaking dengan baik dan benar.

Pada mahasiswa Ilmu Komunikasi, public speaking merupakan hal yang penting dilakukan dengan teknik yang benar. Oleh karena itu, peneliti melakukan penelitian tentang tindakan bullying dalam komunikasi antar pribadi semasa Sekolah Menengah Atas serta dampaknya pada nilai public speaking dan IPK. Penelitian ini dilakukan pada mahasiswa Ilmu Komunikasi semester 2 atau beberapa bulan setelah merasakan peralihan dari sebelumnya siswa menjadi mahasiswa. Mahasiswa Ilmu 
Jesica Sharon Agatha, Roswita Oktavianti: Tindakan Bullying dalam Komunikasi Antarpribadi Semasa SMA dan Dampaknya pada Nilai Public Speaking dan IPK

Komunikasi dituntut memiliki kemampuan berkomunikasi yang baik di depan publik.

Terdapat penelitian terdahulu yang memiliki topik pembahasan serupa dengan penelitian ini. Rohman (2016) melakukan penelitian berjudul "Hubungan Antara Usia, Tingkat Kelas, dan Jenis Kelamin dengan Kecenderungan Menjadi Korban Bullying". Hasil penelitian menyatakan bahwa terdapat hubungan antara tingkat kelas dan jenis kelamin dengan kecenderungan menjadi korban bullying, tetapi tidak terdapat hubungan antara usia dengan kecenderungan menjadi korban bullying di SDN Lowokwaru 3 Malang tahun 2015. Kecenderungan lebih mengarah kepada seluruh tingkat usia, jenis kelamin dan dan kelas. Khoirunnisa (2014) dalam penelitian berjudul "Konsep Diri Remaja Korban Bullying (Studi pada Siswa Korban Bullying di SMA Muhammadiyah 7 Yogyakarta)" menemukan bahwa tindakan bullying bisa mempengaruhi dan juga tidak mempengaruhi konsep diri seseorang. Tindakan bullying mempengaruhi konsep diri jika hal itu ditambah dengan kurangnya keharmonisan dalam keluarga.

\section{Metode Penelitian}

Penelitian ini menggunakan pendekatan campuran (mix method). Metode campuran merupakan metode gabungan dari metode penelitian kuantitatif dan kualitatif (Senjaya, 2018:104) Penelitian ini difokuskan kepada tindakan bullying, kemampuan public speaking yang diukur melalui perolehan nilai public speaking, dan juga kemampuan akademis yang diukur melalui perolehan Indeks Prestasi Kumulatif (IPK). Penelitian ini menggunakan pendekatan metode campuran dengan metode survei dan wawancara terhadap tiga responden yang sesuai dengan kriteria.

Penggalian data dilakukan menggunakan penyebaran kuisioner yang berisi pertanyaan seputar pengalaman bullying semasa SMA, nilai public speaking, dan IPK yang diperoleh pada semester 1. Penarikan sempel menerapkan teknik purposive sample, di mana peneliti menyebarkan kuisioner kepada responden yang memenuhi kriteria penelitian ini. Kriteria tersebut diantaranya responden merupakan mahasiswa aktif Fakultas Ilmu Komunikasi Universitas Tarumanagara, responden merupakan mahasiswa semester dua, responden telah mendapatkan pembelajaran mata kuliah public speaking, responden telah menyelesaikan masa pembelajaran pada semester pertama. Jumlah responden dalam penelitian ditentukan berdasarkan teorema limit sentral yang menyatakan minimum responden dalam sebuah penelitian sebanyak 30 orang. Peneliti menentukan jumlah responden penelitian sebanyak 40 orang responden sesuai kriteria.

Pengukuran data menggunakan skala likert yang merupakan skala dengan menggunakan item yang pasti, baik ataupun buruk, sehingga dapat diketahui seberapa banyak respon tidak pernah mengalami, sampai dengan sangat sering mengalami. Indikator-indikator dari variabel yang digunakan sebagai tolok ukur dalam menyusun pertanyaan ataupun pernyataan yang harus diisi. Masing-masing butir pertanyaan dan pernyataan didukung oleh pilihan jawaban sebagai berikut: (1) Tidak pernah; (2) Tidak Sering; (3) Sering; (4) Sangat Sering.

Menurut Cloroso (2007) terdapat empat jenis (dimensi) bullying, diantaranya adalah bullying fisik, bullying verbal, bullying relasional, cyber bullying (Zakiyah, dkk 2017:327). 


\section{Hasil Penelitian dan Pembahasan}

Berdasarkan hasil penelitian jumlah responden yang diperoleh adalah laki-laki sebanyak 13 orang $(30,2 \%)$ dan perolehan responden perempuan sebanyak 30 orang $(69,8 \%)$. Jumlah responden yang berusia $17-18$ tahun sebanyak 12 orang (27,9\%), dan responden berusia $19-21$ tahun sebanyak 31 orang $(72,1 \%)$. Tidak ada responden dengan kategori 21-22 tahun dan $>22$ tahun $(0 \%)$. Responden yang mengemban pendidikan di SMA/SMK sebanyak 43 (100\%). Sedangkan responden dengan pendidikan homeschooling, tidak ada $(0 \%)$.

\subsection{Frekuensi tanggapan responden terhadap variabel tindakan bullying yang dominan}

Tabel 1. Frekuensi responden yang pernah mengalami bullying fisik dalam bentuk dirusak barang yang dimiliki (misalnya kotak pensil dirusak, tas anda dibanting, barang anda disembunyikan, dll) pada saat SMA/SMK

\begin{tabular}{|c|c|c|c|}
\hline No. & Skala & Frekuensi & Persen \\
\hline 1 & Tidak Pernah & 29 & $72,5 \%$ \\
\hline 2 & Tidak Sering & 8 & $20 \%$ \\
\hline 3 & Sering & 3 & $7,5 \%$ \\
\hline 4 & Sangat Sering & 0 & $0 \%$ \\
\hline \multicolumn{2}{|c|}{ Total } & 40 & $100 \%$ \\
\hline
\end{tabular}

Sumber data: Data Primer, diolah dari kuesioner

Tabel 1 menunjukkan skala jawaban responden terbesar menyatakan "Tidak Pernah" mengalami bullying fisik dalam bentuk dirusak barang yang dimiliki yakni 29 responden (72,5\%). Diikuti skala jawaban terkecil menyatakan "Sangat Sering" (0\%). Responden yang menjawab "Tidak Sering" sebanyak 8 responden (20\%), dan yang menjawab sering sebanyak 3 responden (7,5\%).

Tabel 2. Frekuensi responden yang mengalami bullying verbal berupa hinaan fisik (misalnya bentuk/ukuran tubuh, warna kulit, bentuk wajah, dll) saat SMA/SMK

\begin{tabular}{|c|c|c|c|}
\hline No. & Skala & Frekuensi & Persen \\
\hline 1 & Tidak Pernah & 7 & $17,5 \%$ \\
\hline 2 & Tidak Sering & 19 & $47,5 \%$ \\
\hline 3 & Sering & 6 & $15 \%$ \\
\hline 4 & Sangat Sering & 8 & $20 \%$ \\
\hline \multicolumn{2}{|c|}{ Total } & 40 & $100 \%$ \\
\hline
\end{tabular}

Sumber data: Data Primer, diolah dari kuesioner

Tabel 2 menunjukkan bahwa skala jawaban responden terbesar menyatakan "Tidak Sering" mengalami bullying verbal berupa hinaan fisik saat SMA/SMK 19 $(47,5 \%)$. Skala jawaban responden terkecil menyatakan "Sering" sebanyak 6 responden $(20 \%)$. Kemudian responden yang menjawab "Tidak Pernah" sebanyak 7 responden (17,5\%). Jawaban "Sangat Sering" sebanyak 8 responden (20\%). Berikut kutipan jawaban narasumber terkait bullying verbal berupa hinaan fisik 
Jesica Sharon Agatha, Roswita Oktavianti: Tindakan Bullying dalam Komunikasi Antarpribadi Semasa SMA dan Dampaknya pada Nilai Public Speaking dan IPK

"Jika fisik saya sering dikatakan lemah mungkin karena saya sering bermain dengan teman perempuan... Hinaannya jika saya tidak bisa melakukan sesuatu pasti dibilang "lemah" (Narasumber 1, inisial KT, laki-laki, lokasi SMA di Jakarta Barat)

“...sering terlontar kepada saya itu pasti tentang fisik seperti pendek itu udah pasti banget. Terus ada lagi, ngomongin badannya terlalu kurus, udah terlalu pendek terus kurus, ringkih tau badannya, kasihan liatnya kayak gak dikasih makan. Ya tapi kan karena kebetulan skalanya tidak sering tetapi karena sebenarnya saya merasa hanya candaan dari teman, jadi saya nanggepinnya pun juga gak terlalu yang makan ke hati doang kecuali kalau mungkin mood lagi jelek bisa aja saya jadi marah terus tapi kalau saya lagi marah itu saya memang mengasingkan diri dari temen-temen, jadi saya gak mau nimbulin masalah diantara teman". (Narasumber 2, inisial WC, perempuan, lokasi SMA di Cikupa, Tangerang.

Tabel 3. Frekuensi responden yang mengalami bullying relasional berupa pengucilan (misalnya dijauhi teman satu kelompok tanpa tahu penyebabnya, hanya anda yang tidak diberi tahu informasi penting dari guru, dll) pada saat SMA/SMK

\begin{tabular}{|c|c|c|c|}
\hline No. & Skala & Frekuensi & Persen \\
\hline 1 & Tidak Pernah & 23 & $57,5 \%$ \\
\hline 2 & Tidak Sering & 10 & $25 \%$ \\
\hline 3 & Sering & 3 & $7,5 \%$ \\
\hline 4 & Sangat Sering & 4 & $10 \%$ \\
\hline \multicolumn{2}{|r|}{ Total } & 40 & $100 \%$ \\
\hline
\end{tabular}

Sumber data: Data Primer, diolah dari kuesioner

Tabel 3 menunjukkan bahwa skala jawaban responden terbesar menyatakan "Tidak Pernah" mengalami bullying relasional berupa pengucilan pada saat SMA/SMK sebanyak 23 responden (57,5\%). Skala jawaban responden terkecil yaitu "Sering" sebanyak 3 responden (7,5\%). Sedangkan responden yang menyatakan "Tidak Sering" sebanyak 10 responden (25\%), dan yang menyatakan "Sangat Sering" sebanyak 4 responden $(10 \%)$.

Tabel 4. Frekuensi responden yang pernah mendapat komentar buruk yang dapat dilihat banyak orang di pesan instan dan akun media sosial Anda (Misalnya Whatsapp Grup, Line Grup kelas, dll) pada saat SMA/SMK

\begin{tabular}{|c|c|c|c|}
\hline No. & Skala & Frekuensi & Persen \\
\hline $\mathbf{1}$ & Tidak Pernah & 26 & $65 \%$ \\
\hline $\mathbf{2}$ & Tidak Sering & 9 & $22,5 \%$ \\
\hline $\mathbf{3}$ & Sering & 3 & $7,5 \%$ \\
\hline $\mathbf{4}$ & Sangat Sering & 2 & $5 \%$ \\
\hline \multicolumn{2}{|c|}{ Total } & $\mathbf{4 0}$ & $\mathbf{1 0 0 \%}$ \\
\hline
\end{tabular}

Sumber data: Data Primer, diolah dari kuesioner

Tabel 4 menunjukkan bahwa skala jawaban responden terbesar menyatakan "Tidak Pernah" mendapat komentar buruk yang dapat dilihat banyak orang di pesan instan dan akun media sosial pada saat SMA/SMK sebanyak 26 responden (65\%). Skala jawaban responden terkecil menyatakan "Sangat Sering" sebanyak 2 responden 
(5\%), "Tidak Sering" sebanyak 9 responden $(22,5 \%)$, dan yang menyatakan "Sering" sebanyak 3 responden (7,5\%). Berikut kutipan narasumber KM mengenai bullying relasional yang dialami.

"Dia kayak cari-cari foto-foto aib saya nih yang lagi gimana, dia share di grup dan menertawakan. Itu sih bentuknya, gak lebih parah dari itu sih”. (Narasumber 3, inisial KM, perempuan, lokasi SMA di Jakarta Pusat)

Tabel 1, Tabel 2, Tabel 3, dan Tabel 4 merupakan empat jenis bullying dengan frekuensi bullying yang paling tinggi dialami oleh responden dari penelitian ini. Wawancara dilakukan terhadap tiga narasumber yang memenuhi kriteria berikut : (1) merupakan mahasiswa aktif Fikom Untar; (2) telah menyelesaikan masa pembelajaran semester satu; (3) pernah menjadi korban bullying; (4) telah mendapatkan mata kuliah public speaking.

Berdasarkan hasil wawancara narasumber KT mengalami bullying dominan yaitu bullying verbal berupa fitnah, hinaan fisik, hinaan tentang orang tua, kritik negatif yang berlebihan, dan kata-kata kasar. Selain itu ia juga mengalami bullying relasional berupa pengucilan, dan cyber bullying berupa pesan negatif pada akun media sosial pribadi serta komentar negatif pada media sosial. KT menyatakan bahwa hal ini berdampak pada kemampuan akademiknya yang menurun pada saat ia sedang mengalami tindakan bullying. Akan tetapi, ketika ia memutuskan untuk pindah sekolah kemampuan akademiknya terus meningkat hingga ke perguruan tinggi. Selain itu kemampuan public speaking narasumber KT juga meningkat setelah SMA.

Bullying merupakan suatu tindakan yang telah menjadi pola perilaku. Tindakan ini dapat terjadi dimana saja, baik dalam dunia nyata maupun dunia maya. Dengan kemajuan teknologi yang ada tindakan bullying di dunia maya sangat mudah terjadi dan tersebar luas dengan cepat. Setelah hal tersebut terjadi dengan mudahnya, begitu banyak anak remaja yang melakukan tindakan bunuh diri akibat bullying yang dialaminya (Devito, 2015:195).

Narasumber WC mengalami bullying verbal berupa hinaan fisik, serta hinaan tentang orang tua semasa SMA. Namun, bullying yang dialami tidak berdampak pada nilai public speaking dan IPK. Hal ini karena WC menjadikan situasi saat itu sebagai motivasinya untuk membuktikan kelebihannya pada teman-teman yang melakukan bully.

Narasumber KM mengalami bullying verbal berupa fitnah, hinaan fisik, dan kritik negatif. Narasumber KM juga mengalami bullying relasional berupa pengucilan dan penghindaran yang berujung kepada cyber bullying dengan skala "Sering". KM menyatakan bahwa setelah lulus dari SMA dirinya mengubah seluruh penampilan, dan belajar untuk bekerja. Hal ini melatih keberanian KM untuk kembali percaya diri menyuarakan pendapatnya. Maka KM menyatakan bahwa tindakan bullying yang dialaminya memiliki dampak yang baik pada kemampuan public speaking dan nilai IPK.

\section{Kesimpulan}

Dari keempat jenis tindakan bullying, yaitu bullying fisik, verbal, relasional dan cyber bullying, tindakan bullying yang paling dominan dialami oleh responden adalah bullying verbal. Dari delapan bentuk bullying verbal bentuk yang paling 
dominan dialami yaitu bullying verbal berupa hinaan fisik seperti ukuran tubuh, warna kulit, dan sebagainya.

Tindakan bullying dalam komunikasi antarpribadi semasa SMA memiliki dampak yang berbeda-beda bagi korbannya ketika memasuki jenjang perguruan tinggi atau menjadi mahasiswa. Terdapat mahasiswa yang memiliki nilai public speaking dan IPK rendah akibat tindakan bullying semasa SMA, tetapi ada pula yang mampu memperoleh nilai public speaking dan IPK yang tinggi. Mahasiswa yang mengalami bullying verbal cenderung bisa beradaptasi ketika kuliah sehingga memperoleh nilai IPK dan public speaking yang baik. Namun mahasiswa yang kerap mengalami bullying fisik semasa SMA cenderung lebih sulit beradaptasi saat di perguruan tinggi.

\section{Ucapan Terima Kasih}

Puji Syukur kepada Tuhan Yang Maha Esa oleh karena kasih karunia, rahmat, serta anugerah-Nya peneliti dapat menyelesaikan penelitian ini. Ucapan terima kasih juga peneliti sampaikan kepada dosen pembimbing, teman-teman yang telah memberi dukungan, responden, dan narasumber penelitian.

\section{Daftar Pustaka}

Budyatna. Muhammad, G. (2011). Teori Komunikasi Antarpribadi. Jakarta: Kencana.

Khoirunnisa, R. (2014, Oktober).Konsep Diri Remaja Korban Bullying, Studi pada Siswa Korban Bullying di SMA Muhammadiyah 7 Yogyakarta, Vol. 4,No. 10, $1-13$.

Liliweri. (2015). Komunikasi Antar Personal. Bandung: Citra Aditya Bakti.

Oktavianti, R. (2019, Mei). Belajar Public Speaking sebagai Komunikasi yang

Efektif. Jurnal Bukti Masyarakat Indonesia ISSN 2620-7710, Vol. 2,NO. 1, 117-122.

Rohman, M. Z. (2016). Hubungan Antara Usia, Tingkat Kelas, dan Jenis Kelamin dengan Kecenderungan menjadi Korban Bullying. The 3rd University Research Colloquium, 526-532.

Zakiyah, E. Z. (2011). Faktor yang Mempengaruhi Remaja Melakukan Bullying. Jurnal Penelitian \& PPM, Vol. 4, No. 2, 325-329. 